\title{
Unidades de Conservação: breves aspectos históricos e relevância
}

Conservation Units: brief historical aspects and relevance

Unidades de conservación: breves aspectos históricos y relevancia

Julia de Oliveira Ferreira

Discente, UFSCar, Brasil

ju.ferreira1098@gmail.com

Maira Abgail dos Santos Silva

Discente, UFSCar, Brasil.

Cássia Maria Bonifácio

Professora Doutora, UFSCar, Brasil. cassiabonifacio@hotmail.com 


\title{
Revista Científica ANAP Brasil
}

\author{
ISSN 1984-3240 - Volume 13, número 31, 2020
}

RESUMO

A fim de amenizar a degradação ambiental desenfreada e as perdas ocasionadas pela ação antrópica, surge à necessidade da criação de Unidades de Conservação. A criação destas Unidades teve como embasamento a conservação da biodiversidade, que vem sendo discutida com maior ênfase somente nos últimos anos. Vale destacar que no Brasil até a década de 1970 as questões ambientais não recebiam devida atenção, ou seja, há ainda muito que evoluir na questão da política ambiental no país. Desse modo, o presente trabalho busca apresentar e relatar a importância das Unidades de Conservação, com ênfase em exemplos da região do sudoeste paulista, visando colaborar com a possibilidade de instigar a estudos nessas áreas, uma vez que há pouca bibliografia sobre essas Unidades.

PALAVRAS-CHAVE: Unidades de Conservação. Meio Ambiente. Sudoeste Paulista.

\begin{abstract}
In order to alleviate rampant environmental degradation and as caused by anthropic action, the need for the creation of Conservation Units increases. The creation of these units was based on the conservation of biodiversity, which has been discussed with greater emphasis only in recent years. It is worth mentioning that in Brazil until the 1970s, as environmental issues that do not receive due attention, in other words, there is still much to evolve in the issue of environmental policy in the country. In this way, the present work seeks to present and relate the importance of Conservation Units, with an emphasis on samples from the southwestern region of São Paulo, it helps to collaborate with the possibility of starting studies in these areas, since there is little bibliography on these units.
\end{abstract}

KEYWORDS: Conservation Units. Environment. Southwest Paulista.

\section{RESUMEN}

Con el fin de aliviar la degradación ambiental desenfrenada y causada por la acción antrópica, aumenta la necesidad de crear Unidades de Conservación. La creación de estas unidades se basó en la conservación de la biodiversidad, que se ha discutido con mayor énfasis solo en los últimos años. Vale la pena mencionar que en Brasil hasta la década de 1970, como problemas ambientales que no reciben la debida atención, en otras palabras, todavía hay mucho por evolucionar en el tema de la política ambiental en el país. De esta manera, el presente trabajo busca presentar y relatar la importancia de las Unidades de Conservación, con énfasis en muestras de la región sudoeste de São Paulo, ayuda a colaborar con la posibilidad de iniciar estudios en estas áreas, ya que hay poca bibliografía sobre estas unidades.

PALABRAS CLAVE: Unidades de Conservación. Medio ambiente. Sudoeste Paulista. 


\section{Revista Científica ANAP Brasil}

ISSN 1984-3240 - Volume 13, número 31, 2020

\section{INTRODUÇÃO}

A responsabilidade socioambiental parte do pressuposto de que a humanidade cria uma percepção de que o desenvolvimento acelerado e predatório negligencia as necessidades do meio ambiente, exaurindo os recursos naturais através da superexploração, gerando efeitos catastróficos ao ambiente (NASCIMENTO et al., 2019). A perda da biodiversidade vem sendo discutida e ganhando maior atenção nos últimos anos. Nota-se uma maior preocupação da parte da população em relação às questões ambientais e do modo que esse assunto é abordado e transmitido. Atualmente, a escassez dos recursos naturais traz à tona questionamentos sobre as medidas que devem ser tomadas para amenizar os prejuízos acometidos à natureza (HASSLER, 2005).

Para Cruz, Pilau Sobrinho e Garcia (2014) a crise ecológica é agravada pela ineficácia do planejamento e políticas amplas e de longo prazo, uma vez que os responsáveis pela elaboração e execução das políticas públicas não conseguem abordar e relacionar os problemas ambientais em escala global. Por conta disso, as preocupações giram em torno de problemas visíveis, tais como, queimadas, desmatamento e aterros sanitários, como consequência, a falta de uma abordagem apropriada para a sensibilização da população, resulta na ocultação da real dimensão da crise ecológica e de sua ameaça (CRUZ, PILAU SOBRINHO e GARCIA, 2014).

No Brasil, a elaboração de normativos pioneiros visando à gestão de recursos naturais iniciouse na década de 1930 e, a partir desse marco, o país vem avançando gradualmente nos processos de institucionalização das políticas nacionais de meio ambiente (MOURA, 2016). Até a década de 1960, o foco da política ambiental brasileira era voltado para a administração dos recursos naturais, devido à devastação das florestas para exploração e ocupação inadequada e, além disso, por conta dos interesses individuais de cada setor público, dificultavam na implantação das políticas ambientais (ARANA et al., 2018).

Em contrapartida, de acordo com Figueiredo (2018), na década de 1970 as questões ambientais ainda não recebiam a merecida atenção. Nesta época, o Brasil era reconhecido internacionalmente por possuir uma legislação ambiental muito branda, o que implicava no não cumprimento das leis. Por conta disso, neste mesmo ano, houve uma alteração na política ambiental, a qual agregava aos Planos Nacionais de Desenvolvimento novas estratégias (ARANA et al., 2018).

Em resposta à degradação ambiental desenfreada, a criação de Unidades de Conservação (UCS) tem sido um meio de amenizar as perdas ocasionadas pelo progresso e desenvolvimento humano (MUNGAI, 2008). As UCs foram estabelecidas pelo Sistema Nacional de Unidades de Conservação (SNUC), o qual padroniza as categorias e objetivos de criação e quais estratégias de gestão são mais adequadas para cada unidade (FONSECA; LAMAS; KASECKER, 2010).

O SNUC possui grande importância, uma vez que é uma ferramenta pioneira na busca de listar as mais variadas categorias de UCs existentes no país. Entretanto, apesar do avanço em relação às áreas protegidas no Brasil, o SNUC ainda não conseguiu atingir, ao todo, o seu principal objetivo o qual visa à criação de um sistema que integra, através de um único instrumento, a gestão e criação a fim de sustentar a viabilidade e efetividade das políticas públicas (SILVA; MELLO, 2019). 
Com a criação dessas áreas protegidas por lei, de acordo com Moura (2016), as UCs podem ser utilizadas para a compreensão da realidade e podem vir a ser um modo de sensibilizar as pessoas, bem como trabalhar a interpretação ambiental e o senso crítico. Através dos trabalhos de Educação Ambiental, pode-se gerar um sentimento de pertencimento no resgate do natural, fazendo com que haja um maior envolvimento do público, o que pode resultar na criação de alternativas que venham a contribuir na solução de problemas e tornando o público mais participativo em processos de tomada de decisão (GANEN, 2013).

Desse modo, o presente trabalho busca apresentar e relatar a importância das Unidades de Conservação, abordando exemplos da região do sudoeste paulista. Com isso, este trabalho colabora com a possibilidade de instigar estudos nessas áreas, uma vez que há pouca bibliografia sobre essas Unidades.

\section{OBJETIVO}

Elucidar sobre a importância das Unidades de Conservação (UC) e seus aspectos históricos de criação e manejo, além da apresentação das UCs do sudoeste paulista.

\section{MATERIAIS E MÉTODOS}

A metodologia adotada para o desenvolvimento deste trabalho foi inspirada nos estudos de manejo de unidade de conservação, abordados com maior ênfase pelo Instituto Chico Mendes (ICMBio). Neste sentido o detalhe na escala de análise é dado ao reconhecimento das Unidades de Conservação como meio de conservar a diversidade biológica e os atributos naturais, estéticos e culturais. Neste trabalho, o levantamento sobre as Unidades de Conservação e seus aspectos históricos. Sendo assim, procedeu-se o levantamento bibliográfico acerca dos temas de interesse: "Política ambiental do Brasil", "Sistema Nacional de Unidades de Conservação (SNUC)", "Unidades de conservação", "UCs do Sudoeste Paulista", com o intuito de evidenciar a importância sobre essas temáticas.

\section{RESULTADOS}

\section{- BREVE HISTÓRICO DA POLÍTICA AMBIENTAL NO BRASIL}

O progresso humano, na maioria das vezes, esteve ligado à degradação ambiental. Com a justificativa de desenvolvimento econômico, os recursos naturais foram explorados até chegar ao seu limite (MORETI et al., 2017). Por conta disso, na década de 1950, surgiram as primeiras entidades voltadas à conservação ambiental, mas, somente na década de 1970 que tais entidades ganharam força, sendo consideradas referências para o movimento conservacionista brasileiro (CARVALHO, 1993). Em 1970, as ações ambientais ganharam notoriedade, neste sentido, destaca-se o Rio Grande do Sul, onde se instituiu um setor de ecologia fundado por Magda Renner, que se tornou reconhecido nacional e internacionalmente (NOAL, 1999).

Com Chico Mendes, o movimento ambiental ganhou a opinião pública, com a divulgação da luta 


\title{
Revista Científica ANAP Brasil
}

\author{
ISSN 1984-3240 - Volume 13, número 31, 2020
}

pelas reservas extrativistas como sendo uma das causas ambientais, propondo a sustentabilidade social e ambiental (MENDES, 1989). Assim, houve uma ação bem-sucedida na qual foi possível trazer a união entre o popular e o ecológico, construindo um ideal ambiental popular incluindo uma luta cidadã ao movimento de preservação (HERCULANO, 1996).

É importante destacar também a ECO-92, que foi significativa e representou um momento histórico ambiental. Por meio desse evento houve a aproximação de líderes, movimentos e organizações de importância da discussão ambiental. A partir daí a luta passa a estar atrelada a questões sociais em geral e ganha visibilidade mundial, o que a deixa cada vez mais forte e mais potente nos debates ambientais (CARVALHO, 1993).

Na década de 1990, a internet e as redes sociais se mostraram aliadas, com notícias que chamaram a atenção para natureza, para preservação. Neste sentido, foram convocadas e organizadas manifestações que tiveram muita importância para conservação. Assim os movimentos ambientais foram evoluindo, a cada dia mais conectados e ganhando mais forças (CRESPO, 1997).

\section{- O SISTEMA NACIONAL DE UNIDADES DE CONSERVAÇÃO (SNUC)}

O breve histórico mencionado anteriormente esclarece que as questões ambientais estão relacionadas ao bem-estar humano (ROSS, 2006). Neste sentido, Medeiros et al., (2011) destacam que houve um marco histórico para conservação da biodiversidade brasileira - a consolidação do SNUC (Sistema Nacional de Unidades de Conservação).

Em 1972, após a Conferência das Nações Unidas em Estocolmo, cuja reunião abordou assuntos voltados aos limites do crescimento econômico, visando o esgotamento dos recursos naturais, notou-se a necessidade de organizar um sistema de critérios e normas para a criação de áreas protegidas (SILVA; MELLO, 2019).

Sendo assim, o SNUC foi criado com a finalidade de regulamentar e preservar o patrimônio ambiental brasileiro, para que as utilidades sociais e culturais da natureza fossem atribuídas como ferramentas na gestão e conservação do meio ambiente, sem dispensar os saberes e valores locais (PROST; SANTOS, 2016; MARRA, 2011). Seu principal objetivo foi/é estabelecer critérios para a implementação e gestão das Unidades de Conservação (UCs), bem como, promover a conservação dos recursos naturais, fortalecer o desenvolvimento sustentável, recuperar áreas degradadas, prover o incentivo a pesquisa e valorizar as comunidades tradicionais (GELUDA, 2005).

- UNIDADES DE CONSERVAÇÃO: Um parâmetro Nacional e Internacional

Segundo Medeiros (2011) no território brasileiro há uma área de $1.278 .190 \mathrm{~km}^{2}$ que são compostas por Unidades de Conversação, as quais são de suma importância para a preservação da biodiversidade. Exemplo disso, destaca-se o Projeto Maracanãs (2016) que visa subsidiar a reintrodução da ararinha-azul e a implementação da Unidade de Conservação Federal no município de Curaçá (BA). Esse projeto realizou um levantamento onde foram encontradas cinco espécies ameaçadas de extinção e duas quase ameaçadas. Essa área é considerada de alta 


\section{Revista Científica ANAP Brasil}

ISSN 1984-3240 - Volume 13, número 31, 2020

prioridade para a conservação da Caatinga. Além disso, a comunidade ao entorno, ressalta a importância da mesma para a biodiversidade e preservação deste bioma, além de ser fundamental para a introdução da ararinha-azul (LUGARINI,2017).

Ainda no Nordeste, a Área de Proteção Ambiental (APA) Chapada do Araripe, cuja unidade compreende 33 municípios dos Estados do Ceará, Piauí e Pernambuco, conseguiu elaborar, por meio dos conhecimentos tradicionais das comunidades locais e do saber científico, uma lista de espécies vegetais que necessitam de ações de conservação. Por meio desta parceria, obteve-se um número de 52 espécies de plantas que necessitam de medidas de preservação. É importante destacar o papel essencial da área de proteção para a continuidade de tais espécies no meio (DOMINGOS, 2016). Deste modo, é evidente que a participação efetiva da população é de extrema importância, uma vez que é papel da Unidade de Conservação de conservar a diversidade biológica, além dos atributos naturais (estéticos e culturais) que provém à qualidade de vida e bem-estar das populações humanas. (MMA, 2019).

Fora do Brasil, há exemplos ainda mais evidentes da importância da conservação ambiental, no caso dos Estados Unidos, o país possui uma área de $2.607 .132 \mathrm{~km}^{2}$ de área preservada. Nestas áreas o investimento gira em torno de $\$ 156,12$ dólares por hectare enquanto que no Brasil são investidos apenas $R \$ 4,43$ reais (MEDEIROS, 2011). Na cultura norte-americana foi difundida a importância do conhecimento da história natural, e, esse interesse da população pela natureza ajuda na popularização das Unidades de Conservação (BRAGA, 2011). Neste caso, ressalta a importância de transmitir informações e dados sobre a biodiversidade, usando como ferramenta a educação ambiental para promover e incentivar a participação da população nas questões ambientais.

Como consequência desse envolvimento público, no exemplo supracitado, as unidades têm uma possibilidade de renda com turismo. Só no ano de 2012 o Parque de Yellowstone recebeu o total de 3.447.729 visitantes, arrecadando uma quantia de 230 milhões de dólares (COLLINS, 2014). Essa popularização só é possível devida à difusão da ciência no país, na qual desde cedo as pessoas têm contato com animais em feiras de ciência nas escolas e, além disso, são sempre incentivadas a conhecer mais sobre a biologia de cada espécie (COLLINS, 2014).

\section{- UCS DO SUDOESTE PAULISTA}

O Sudoeste Paulista, abrange a área de 15 municípios, sendo: Barão de Antonina, Bom Sucesso de Itararé, Buri, Capão Bonito, Coronel Macedo, Guapiara, Itaberá, Itapeva, Itaporanga, Itararé, Nova Campina, Ribeirão Grande, Riversul, Taquarituba e Taquarivaí (FAVORETO, 2007). Destes municípios, apenas quatro possuem uma Unidade de Conservação, sendo elas: Floresta Nacional 
de Capão Bonito (Flona de Capão Bonito), localizada entre os municípios de Buri e Capão Bonito, Estação Ecológica (ESEC) de Itapeva e Estação Ecológica (ESEC) de Itaberá. A Flona de Capão Bonito foi criada através da Portaria 558, de 25 de outubro de 1968 (BRASIL, 1968), sua área total corresponde a 4.344 ha e ao decorrer dos anos, a Unidade de Conservação (UC) teve sua paisagem modificada por conta de atividades agrícolas e da rodovia que a divide em duas partes (SANTOS; MELO; CARDOSO-LEITE, 2019; MATOS, 2015).

A Estação Ecológica (ESEC) de Itapeva, localizada no município de mesmo nome, foi criada pelo Decreto Estadual no 7.692/76, possui uma área de 107 ha a qual, está delimitada ao norte pela SP 258 (Rodovia Francisco Alves Negrão); ao sul, encontra-se o assentamento rural de Pirituba II área IV; a leste e oeste, encontram-se o rio Pirituba e o córrego do Banhado, respectivamente (CIELO-FILHO et al., 2012).

Por fim a ESEC de Itaberá, também localizada no município de mesmo nome, foi criada através do Decreto Estadual no 26.890/87, possui uma área de 180 ha, na qual, corresponde a um fragmento de Floresta Ombrófila Mista, cujo trecho há indícios de ações antrópicas (RIBEIRO, 2011).

Vale ressaltar que estas unidades de conservação estão bem distantes umas das outras, não havendo qualquer fragmento de conectividade que possa colaborar para a dispersão da biodiversidade.

\section{CONCLUSÃO}

As Unidades de Conservação, assim como as Florestas Nacionais, são opções viáveis e importantes para conservação, pesquisa e turismo nas regiões onde estão presentes. Essas reservas desenvolvem um papel chave na conservação de espécies frente à supressão vegetal, principalmente em regiões como o sudoeste paulista. Todavia, conforme apresentado, mostrase necessário um maior investimento, um manejo adequado e infraestrutura para esses locais, para que além de ser ponto de preservação, possam ser locais de referência em pesquisa e turismo. Pode-se afirmar que as UCs citadas estão bem distantes umas das outras, logo, surge à necessidade de divulgar a importância de cada uma, além de destacar sobre seus objetivos e suas contribuições para a conservação da biodiversidade do Sudoeste Paulista.

\section{AGRADECIMENTO}

As autoras agradecem à Beatriz Beisiegel.

\section{REFERÊNCIAS BIBLIOGRÁFICAS}

ARANA, A. R. A., Gestão das águas e planejamento ambiental: áreas de preservação permanente no manancial do alto curso do rio Santo Anastácio - SP. Revista Brasileira de Geografia Física, v. 11, n. 2, p.674-686, nov. 2018.

BRAGA, A. S. Parques Nacionais nos Estados Unidos. Revista Jus Navigandi, ISSN 1518-4862, Teresina, ano 16, $\mathrm{n}$. 2961, 10 ago. 2011.

CARVALHO, I. C. M. Educação Ambiental e Movimentos Sociais: elementos para uma história política do campo ambiental. Educação: teoria e prática, Rio Claro, UNESP-IB, p. 46-56, 1993. 


\section{Revista Científica ANAP Brasil}

ISSN 1984-3240 - Volume 13, número 31, 2020

CIELO-FILHO, R.; AGUIAR, O. T.; BAITELLO, J. B.; PASTORE, J. A., et al. Aspectos florísticos da Estação Ecológica de Itapeva, SP: uma Unidade de Conservação no limite meridional do bioma Cerrado. Biota Neotropica, [s.I.], v. 12, n. 2, p.147-166, jun. 2012.

COLLINS, Deb (Org.). Modelos de concessão em parques norte-americanos. 2014. Disponível em:

<http://www.semeia.org.br/admuploads/uploads/Novembro_Modelos_de_

concessao_em_parques_norte_americanos_13_10.pdf>. Acesso em: 28 nov. 2019.

CRESPO, S. O presente e o futuro do movimento ambientalista na Brasil. In : SVIRSKY, E. e CAPOBIANCO, J.P. (Orgs.) Ambientalismo no Brasil, passado, presente e futuro. São Paulo: Instituto Socioambiental e Secretaria de Meio Ambiente, 1997.

CRUZ, P. M., PILAU SOBRINHO, L., GARCIA, M. L. Meio Ambiente, Transnacionalidade e Sustentabilidade. Itajaí - SC: Univali, 2014. 212 p. Disponível em: <https://www. univali.br/vidanocampus/e ditoraunivali/ebooks/Documents/ecjs /Ebook\%202014\%20MEIO\%20AMBIENTE,\%20TRANSNACIONALIDADE\%20E\%2OSUSTENTABILIDADE\%20\%20VOLUME\%20II.pdf>. Acesso em: nov. 2019.

DOMINGOS, F. R.; SOUZA, P. F. M. ; SOUZA, B. V. Construção coletiva de boas práticas para manejo do pequizeiro (Caryocar coriaceum Vittm.) na chapada do Araripe, Caatinga, Brasil. In: Simpósio Brasileiro de Etnobiologia e Etnoecologia, 2016, Feira de Santana, BA. Anais do XI Simpósio Brasileiro de Etnobiologia e Etnoecologia. Arte Editora, 2016. p. 579-579.

FAVARETO, A. Plano territorial de desenvolvimento rural sustentável do sudoeste paulista (SP). Itapeva: Ministerio do Desenvolvimento Agrário, 2007. 73 p. Disponível em:

<http://sit.mda.gov.br/download/ptdrs/ptdrs_territorio089.pdf>. Acesso em: dez. 2019.

FONSECA, M.; LAMAS, I.; KASECKER, T. O papel das Unidades de Conservação. Scientific American Brasil, [s.I.]. p.1823, maio 2010.

GANEM, R. S. (Org.). Legislação Brasileira sobre meio ambiente. Brasília Câmara dos Deputados, 2013 v.1. (Fundamentos constitucionais e legais).

GELUDA, L. Pagamentos por serviços ecossistêmicos previstos na lei do SNUC: teoria, potencialidades e relevância. 2005. 29 f. TCC (Graduação) - Curso de Ciências Ambientais, UFRJ, Rio de Janeiro, 2005. Disponível em: <http://www.ie.ufrj.br/gema/pdfs/PFC\%20-\%20Leonardo\%20Geluda.pdf>. Acesso em: dez. 2019.

HASSALER, M. L. A importância das Unidades de Conservação no Brasil. Sociedade e Natureza, Uberlândia, v. 33, n. 17, p.79-89, 2005.

HERCULANO, S. O campo do ecologismo no Brasil: o Fórum das ONGs. In: REIS, E.; ALMEIDA, M. E.; FRY, P. (Orgs). Política e cultura: visões do passado e perspectivas contemporâneas. São Paulo: Editora HUCITEC e ANPOCS, 1996.

LUGARINI, C. Projeto com a Maracanã-Verdadeira subsidiará a reintrodução da Ararinha-Azul na natureza. In: Boas Práticas Na Gestão De Unidades De Conservação, 2017, Brasília. Boas Práticas Na Gestão De Unidades De Conservação. Brasília: ICMBio, 2017. v. 1. p. 22-25.

MARRA, Natalia Cardoso. Identidades culturais e a sustentabilidade na criação de parques ambientais. Prisma Juridico, [s.l.], v. 10, n. 2, p.349-367, 28 fev. 2012. University Nove de Julho. http://dx.doi.org/10.5585/prismaj.v10i2.2662.

MATOS, T. P. V. Avaliação da conectividade de remanescentes de vegetação nativa em matriz agrícola, considerando os índices ecológicos para aves. 2015. 58 f. (Dissertação de Mestrado) (Mestrado em Diversidade Biológica e Conservação) - Universidade Federal de São Carlos, Sorocaba, 2015.

MEDEIROS, R.; YOUNG; C. E. F.; PAVESE, H. B.; ARAÚJO, F. F. S. 2011. Contribuição das Unidades de Conservação brasileiras para a economia nacional: Sumário Executivo. Brasília: UNEP-WCMC, $44 p$

MENDES, C. Depoimento. São Paulo, Sindicato dos trabalhadores rurais de Xapuri, Conselho Nacional dos Seringueiros (CNS) e Central Única dos Trabalhadores (CUT), 1989. 


\section{Revista Científica ANAP Brasil}

ISSN 1984-3240 - Volume 13, número 31, 2020

MMA, ICMBIO [online]. Disponível em: <https://www.mma.gov.br/florestas/programa-nacional-de-florestas> Acesso em: nov. de 2019.

MORETI, G. B.; TAMIOSSO, C. F.; TAMIOSSO, M. F.; SWAROWSKY, A. LEGISLAÇÃO AMBIENTAL: REVISÃO DOS ASPECTOS GERAIS DA POLÍTICA NACIONAL DO MEIO AMBIENTE. Disciplinarum Scientia, [s.I], v. 18, n. 2, p.253-264, ago. 2017.

MOURA, A. M. M. Trajetória da política ambiental federal do Brasil. In: MOURA, Adriana Maria Magalhães de. Governança Ambiental no Brasil: instituições, atores e políticas públicas. Brasília: Ipea, 2016. Cap. 1. p. 13-44.

MUNGAI, M. F. Mosaico de interesses, representações e conflitos: o Parque Nacional Cavernas do Peruaçu-MG. 2008. 201 f. Dissertação (Mestrado) - Curso de Geografia, UFMG, Belo Horizonte, 2008.

NASCIMENTO, F. C. F. S.; NASCIMENTO, T. G.; RAMOS, J. C.; MORAIS, A. R. M. N.; et al. Ética e responsabilidade socioambiental. Revista Multidisciplinar e de Psicologia, [s.I.], v. 13, n. 43, p.1043-1055, 2019.

NOAL, F.O. O movimento ecologista no Rio Grande do Sul: Uma abordagem histórico-social no período de 1970 a 1995. 1999. Dissertação (Mestrado) - UNISC.

PROST, C.; SANTOS; M. A. Gestão territorial em Unidades de Conservação de Uso Sustentável e incoerências no SNUC. Novos Cadernos Naea, [s.I], v. 19, n. 1, p.143-158, 2016.

RAMOS, Marli et al. Dispersão e impacto de Pinus elliottii Engelm. var. elliottii em área ripária na Floresta Nacional de Capão Bonito - SP. Ciência Florestal, [s.I.], v. 29, n. 1, p.75-85, 4 abr. 2019. Universidad Federal de Santa Maria. $<$ http://dx.doi.org/10.5902/1980509825789>

RIBEIRO, Tiago Maciel. Florística e estrutura da comunidade arbustivo-arbórea em florestas naturais e restauradas com Araucaria angustifólia (Bertol.) O. Kuntze no Estado de São Paulo, Brasil. 2011. 261 f. Dissertação (Mestrado) - Curso de Ciência Florestal, Universidade de Federal de Viçosa, Viçosa, MG, 2011.

SANTOS, M. T.; MELO, I. B. N.; CARDOSO-LEITE, E. Análise do potencial e da demanda de visitação da Floresta Nacional de Capão Bonito (SP). Revista Brasileira de Ecoturismo, São Paulo, v.12, n.1, fev/abr2019, pp.36-54.

SILVA, A. R.; MELLO, J. S.. Viabilidade de políticas públicas no sistema nacional das unidades de conservação da natureza - SNUC (LEI № 9.985/2000). Revista Processus de Políticas Públicas e Desenvolvimento Social, [S.I.], v. 1, n. 2, p. 71-107, nov. 2019. 